\title{
Alarm Thresholds for Smoke Detector Modeling
}

\author{
JUSTIN A. GEIMAN and DANIEL T. GOTTUK \\ Hughes Associates, Inc. \\ Baltimore, MD 21227, USA
}

\begin{abstract}
Models have been used to estimate smoke detector alarm times by calculating smoke optical densities resulting from fires and correlating the smoke value to an alarm threshold of the detector. This work evaluated the use of smoke optical densities outside a detector as criteria for predicting smoke detector responses. Results are presented for optical density alarm thresholds corresponding to when 20, 50 and 80 percent of the detectors had alarmed in full-scale tests. The data showed that there was a large amount of variability in the measured smoke optical density values outside a detector at the time of alarm. Major variables evaluated included detector type, fire type and nominal detector sensitivity. This evaluation also examined experimental smoke optical density data at the time of detector alarms and compared these smoke values to alarm thresholds recommended in the literature.
\end{abstract}

KEYWORDS: smoke detectors, detector response, optical density, alarm thresholds, sensitivity

\section{INTRODUCTION}

With the increasing use of performance-based fire protection design, it is imperative that predictive tools and methodologies be available to design and analyze fire detection systems. Presently, there are two basic methodologies in use for estimating the response of smoke detectors - the Temperature Rise Method and the Optical Density Method $[1,2]$.

The basic principle of the Temperature Rise Method is that the ratio of the optical density to temperature rise is approximately constant for a given fuel and combustion mode [3]. However, the latter part of this definition is often ignored and temperature rise values ranging from 10 to $15^{\circ} \mathrm{C}$ are used as alarm thresholds for all detectors and fires [1]. This method has been criticized; numerous studies have stated that this relationship has little or no basis $[4,5,6,7]$, while others have gone as far as saying that it simply does not exist [8]. Mowrer [9], Gottuk [10], and Wakelin [11] have shown smoke detector alarms occurring at temperature rises as low as 1 to $3^{\circ} \mathrm{C}$. Due to the highly questionable accuracy of the Temperature Rise Method, this methodology is not going to be addressed in this study.

The Optical Density Method consists of directly calculating the smoke concentration at the detector and comparing the smoke level to an alarm threshold for the detector. Using the mass loss of the fuel, the volume into which the smoke is dissipated, and an empirically determined constant for the fuel, $\mathrm{D}_{\text {mass }}$, an optical density can be determined. Calculation procedures are outlined in $[1,2,7]$. Incorporating these calculations as part of a zone or CFD model allows one to determine the optical density at the detector location. 
Assuming that the optical density at the detector location can be determined, an alarm threshold must be selected in order to determine when the detector will alarm.

Currently, there is little guidance on the selection of the threshold optical density at which a detector will alarm [7]. This is due in part to the many variables, such as fuel type, detector design, burning mode, and smoke aging, that affect the response of a smoke detector. Despite a lack of supporting research, the nominal sensitivity of the detector is often used to determine smoke detector response [8]. For this report, the nominal sensitivity is the alarm level marked on the detector, as determined by the appropriate detector sensitivity test (i.e., UL 217 or 268 [12,13]). Others have suggested using the UL upper limit specification of $0.14 \mathrm{OD} / \mathrm{m}$ as a rough estimate of the optical density at which detectors are likely to operate $[1,2]$. This value corresponds to the maximum allowable black smoke optical density of $10 \% / \mathrm{ft}$ in the UL 217 \& 268 sensitivity tests ${ }^{* \dagger}$. There is little research to substantiate these recommendations for using the nominal sensitivity of the detector or $0.14 \mathrm{OD} / \mathrm{m}$ as an alarm threshold. In fact, there is general agreement that the measured smoke optical density at detector response varies widely $[5,14]$.

The goal of this research was to evaluate the accuracy of using smoke optical density alarm thresholds as criteria for predicting smoke detector responses via the Optical Density Method. The study provides guidance on determining appropriate values for the alarm threshold based on existing full-scale data. This guidance is derived from test data in which optical density measurements were taken immediately adjacent to smoke detectors. A comparison of the optical densities adjacent to the detectors and various alarm thresholds are the basis of the guidance provided. This analysis evaluates data from three test series. The primary variables considered in this analysis are the detector type (ionization or photoelectric), fire type (flaming or smoldering), and nominal detector sensitivity. A more detailed account of this study is provided in [15]. Evaluations of using the nominal sensitivity of the detector and $0.14 \mathrm{OD} / \mathrm{m}$ as alarm thresholds are presented.

\section{METHODOLOGY}

This section provides an overview of the methods used in formulating the analysis that will follow. Each of the data sets used in this analysis are described briefly.

\section{Data Sets}

The database for this analysis is comprised of three independent series of tests, designated as the 1) Indiana Dunes [16], 2) Navy [10,17,18], and 3) Fire Research Station (FRS) [14] data sets. Each of these data sets are described in further detail later in this section. The rationale for selecting these test series was that they all included full-scale fire tests in which both smoke detectors and optical density meters (ODM) were used in close proximity to one another. Another factor was that the detection time and optical density data was presented in the literature or was readily accessible to the authors. The

\footnotetext{
* This black smoke test is no longer conducted as part of the UL 217 and UL 268 detector sensitivity tests

${ }^{\dagger}$ The value of $0.14 \mathrm{OD} / \mathrm{m}$ is from [1] and [2], although a more accurate conversion of $10 \% / \mathrm{ft}$ is $0.15 \mathrm{OD} / \mathrm{m}$
} 
data sets used encompass a range of smoke sources, detector sensitivity levels, test conditions, and detector manufacturers; however, all detectors used in this study were listed by Underwriters Laboratory according to the appropriate sensitivity standard (UL 217 or UL 268).

\section{Indiana Dunes}

The Indiana Dunes data set refers to the full scale residential fire detection tests conducted by IIT Research Institute and Underwriter's Laboratories in the mid-1970's under the sponsorship of the National Bureau of Standards [16]. Despite the age of this research and the technological changes that have occurred since the study, the Indiana Dunes test series is still one of the most important sources of full-scale experimental fire detection tests. Many of the requirements in the UL standards and NFPA 72 are based on the results of this test series.

A range of smoldering and flaming fires were used to represent potential residential fires in the Indiana Dunes test series. Examples of fire sources used in this test series include upholstered chairs, sofas, mattresses, box springs, electrical wiring, and carpet. Tests were conducted in several single-family dwellings with various smoke detector types positioned throughout the houses. For the purposes of this analysis only the ionization and photoelectric detectors were studied. At each detector location there were two ionization and two photoelectric detectors, one at $0.0143 \mathrm{OD} / \mathrm{m}(1 \% / \mathrm{ft})$ nominal sensitivity and one at $0.0288 \mathrm{OD} / \mathrm{m}(2 \% / \mathrm{ft})$ nominal sensitivity. Both wall and ceiling mounted detector orientations were used in the Indiana Dunes tests. Optical density meters were located on the ceiling adjacent to the detector locations in the exit pathways. The optical density meters were constructed with a white light lamp and photocell using a $1.52 \mathrm{~m}(5 \mathrm{ft})$ path length.

\section{Navy}

The Navy data set refers to two series of tests conducted in conjunction with the development of a multi-sensor, multi-criteria fire detector for the U.S. Navy. The first series of tests [10,17] included numerous fire tests of a wide range of materials (smoldering and flaming) in a closed room approximately $4.1 \times 6.5 \times 3.6 \mathrm{~m}$ high (13 x 21 x $12 \mathrm{ft}$ ). Examples of materials used in these fire tests include flammable liquids, mattresses, electrical cable, linens, paper/cardboard, and oily rags. Commercial (UL 268 listed) ionization and photoelectric smoke detectors were suspended $0.3 \mathrm{~m}$ below the ceiling (i.e. the depth of beams on which detectors are typically mounted), $4.5 \mathrm{~m}(14.8 \mathrm{ft})$ from the fire sources. The second series of tests [18] were conducted onboard the ExUSS Shadwell [19] in a space approximately $8.5 \times 8.5 \times 3 \mathrm{~m}$ high $(28 \times 28 \times 10 \mathrm{ft})$. These tests also included a wide range of smoldering and flaming fire sources exposed to the same commercial smoke detectors used in the first series. Direct output from these detectors were available, which allowed the detectors to be evaluated at multiple alarm sensitivity levels. The following alarm levels were studied: 0.0071 and $0.0186 \mathrm{OD} / \mathrm{m}$ $(0.5$ and $1.3 \% / \mathrm{ft})$ for ionization and $0.0071,0.0361$ and $0.0508 \mathrm{OD} / \mathrm{m}(0.5,2.5$ and 3.5 $\% / \mathrm{ft}$ ) for photoelectric. The smoke optical density measurements were made within 0.3 to $0.6 \mathrm{~m}$ of the detectors using white light lamps and photocells and a $1.52 \mathrm{~m}(5 \mathrm{ft})$ path length. 
The FRS data set refers to tests conducted by Mike Spearpoint and Nigel Smithies of the Fire Research Station, on behalf of the Home Office Fire Research and Development Group [14]. The FRS tests were a series of eleven tests conducted in a typical two-story UK dwelling that evaluated smoke detector performance and detector sensitivity standards. FRS examined the times to hazardous visibility conditions, the response of detectors to standard sensitivity test smoke sources, a relative comparison of US versus UK smoke detectors, as well as the optical density at the time of alarm.

Nine of the eleven FRS tests were conducted according to the guidelines of BS 5445 (1984 TF 2-5) for testing fire detector sensitivity. Examples of these sources include polyurethane foam, cotton wicks, flammable liquids and smoldering wood on a hot plate. The two remaining fires were ad hoc fires developed to represent realistic fire sources in residential dwellings (i.e. cooking oil and upholstered furniture).

Both US (UL listed) and UK (BS listed) ionization and photoelectric detectors were tested in the FRS study. For the purposes of this analysis only the UL listed ionization and photoelectric detectors were studied. The UL 268 listed detectors had sensitivity levels of $0.0129 \mathrm{OD} / \mathrm{m}(0.9 \% / \mathrm{ft})$ and $0.0295 \mathrm{OD} / \mathrm{m}(2.05 \% / \mathrm{ft})$ for the ionization and photoelectric detectors respectively. The UL 217 listed detectors had sensitivity levels of $0.023 \mathrm{OD} / \mathrm{m}(1.6 \% / \mathrm{ft})$ and $0.027 \mathrm{OD} / \mathrm{m}(1.88 \% / \mathrm{ft})$ for the ionization and photoelectric detectors respectively. Detectors were located in four locations in the dwelling - ground floor lounge, ground floor hall, first floor bedroom, and first floor landing - at ceiling level.

Optical density meters were located immediately below and central to the detector locations, nominally $100 \mathrm{~mm}$ below the ceiling. The optical density meters were constructed with a broad-spectrum white light tungsten lamp and a nominal 1.0 meter path length.

\section{RESULTS \& ANALYSIS}

An effort was made to identify a range of alarm thresholds based on the optical density meter (ODM) measurements that could be used to determine whether a smoke detector would be in alarm. Toward this end, the term Optical Density Alarm Threshold (OD Alarm Threshold) was defined to represent the optical density level at which a certain percentage of detectors would have alarmed based on the test data evaluated. OD Alarm Thresholds of 20, 50, and 80 percent were selected to provide a range of typical values that could be used depending on the application. Further rationale for and values of the OD Alarm Thresholds are presented below. In addition, results obtained from evaluating the nominal detector sensitivity and $0.14 \mathrm{OD} / \mathrm{m}$ as alarm thresholds are presented.

\section{OD Alarm Threshold}

The OD Alarm Threshold is defined for this study as the smoke optical density level at which a certain percentage of detectors would have alarmed based on actual test data. Therefore, to predict detector activation based on smoke optical density measurements outside the detector, the OD Alarm Threshold provides a threshold criterion at which a given percentage of detectors will likely alarm. Based on the data sets studied, using values of $20 \%, 50 \%$, and $80 \%$ of the population for the OD Alarm Threshold provided reasonable thresholds at a justifiable resolution; i.e., defining thresholds at 5 or 10 percent 
increments of the available population was not sound given the small sample sizes. The vast majority of the data sets did not have any more than 50 detectors of a given fire and detector type and nominal sensitivity, with some only in the 10 to 20 detector range (see Table 1). Based on an informal sensitivity analysis, it was concluded that using a percentage greater than $80 \%$ or less than $20 \%$ of the population could result in one or two anomalous tests inappropriately skewing the OD Alarm Thresholds.

Table 1 presents the 20, 50, and 80 percent OD Alarm Thresholds. In addition, the arithmetic mean ODM value at the detector alarm time for each case is also presented with the standard deviation. These values are provided to demonstrate the tremendous variation in the data and to establish a rationale for using percentiles of the population for this analysis. In fact, examining the range within one standard deviation of the mean can result in non-physical, negative values for the optical density at alarm time. This is an artifact of the statistics due to the right- or positive-skewed distributions of the optical density values at alarm time and the presence of values much larger than the mean. The last column is the number of detectors examined.

\section{Table 1 - OD Alarm Thresholds}

\begin{tabular}{|c|c|c|c|c|c|c|c|c|c|}
\hline \multirow[t]{2}{*}{ Test Series } & \multirow[t]{2}{*}{$\begin{array}{c}\text { Detector } \\
\text { Type }\end{array}$} & \multirow{2}{*}{$\begin{array}{c}\text { Nominal } \\
\text { Sensitivity } \\
(\mathrm{OD} / \mathrm{m})\end{array}$} & \multirow[t]{2}{*}{$\begin{array}{c}\text { Fire } \\
\text { Source }^{\mathrm{a}}\end{array}$} & \multicolumn{3}{|c|}{$\begin{array}{c}\text { ODM Alarm Thresholds } \\
(\mathrm{OD} / \mathrm{m})\end{array}$} & \multicolumn{2}{|c|}{$\begin{array}{l}\text { ODM Value at } \\
\text { Alarm }(\mathrm{OD} / \mathrm{m})\end{array}$} & \multirow[t]{2}{*}{ \# Dets } \\
\hline & & & & $20 \%$ & $50 \%$ & $80 \%$ & Mean & \begin{tabular}{|l|} 
Std Dev \\
\end{tabular} & \\
\hline Indiana Dunes & Ion & 0.0143 & $\mathrm{~F}$ & 0.003 & 0.015 & 0.090 & 0.060 & 0.117 & 49 \\
\hline Indiana Dunes & Photo & 0.0143 & $\mathrm{~F}$ & 0.018 & 0.045 & 0.118 & 0.138 & 0.237 & 42 \\
\hline Indiana Dunes & Ion & 0.0288 & $\mathrm{~F}$ & 0.003 & 0.024 & 0.116 & 0.081 & 0.133 & 54 \\
\hline Indiana Dunes & Photo & 0.0288 & $\mathrm{~F}$ & 0.022 & 0.057 & 0.118 & 0.138 & 0.227 & 41 \\
\hline Indiana Dunes & Ion & 0.0143 & $\mathrm{~S}$ & 0.032 & 0.078 & 0.186 & 0.111 & 0.098 & 83 \\
\hline Indiana Dunes & Photo & 0.0143 & $\mathrm{~S}$ & 0.021 & 0.040 & 0.087 & 0.074 & 0.111 & 69 \\
\hline Indiana Dunes & Ion & 0.0288 & $\mathrm{~S}$ & 0.057 & 0.127 & 0.186 & 0.149 & 0.136 & 96 \\
\hline Indiana Dunes & Photo & 0.0288 & $\mathrm{~S}$ & 0.033 & 0.057 & 0.118 & 0.082 & 0.084 & 76 \\
\hline Navy & Ion & 0.0071 & $\mathrm{~F}$ & 0.007 & 0.015 & 0.044 & 0.025 & 0.026 & 46 \\
\hline Navy & Photo & 0.0071 & $\mathrm{~F}$ & 0.012 & 0.028 & 0.056 & 0.031 & 0.026 & 43 \\
\hline Navy & Ion & 0.0186 & $\mathrm{~F}$ & 0.011 & 0.022 & 0.065 & 0.034 & 0.037 & 45 \\
\hline Navy & Photo & 0.0361 & $\mathrm{~F}$ & 0.028 & 0.049 & 0.057 & 0.055 & 0.046 & 14 \\
\hline Navy & Photo & 0.0508 & $\mathrm{~F}$ & 0.044 & 0.068 & 0.121 & 0.082 & 0.049 & 22 \\
\hline Navy & Ion & 0.0071 & $\mathrm{~S}$ & 0.028 & 0.081 & 0.116 & 0.079 & 0.049 & 18 \\
\hline Navy & Photo & 0.0071 & $\mathrm{~S}$ & 0.028 & 0.042 & 0.066 & 0.061 & 0.057 & 25 \\
\hline Navy & Ion & 0.0186 & $\mathrm{~S}$ & 0.025 & 0.090 & 0.138 & 0.082 & 0.057 & 14 \\
\hline Navy & Photo & 0.0361 & $\mathrm{~S}$ & 0.030 & 0.065 & 0.076 & 0.074 & 0.065 & 6 \\
\hline Navy & Photo & 0.0508 & $\mathrm{~S}$ & 0.063 & 0.079 & 0.125 & 0.093 & 0.046 & 20 \\
\hline$\overline{\text { FRS }}$ & Ion & 0.0129 & $\bar{F}$ & 0.013 & 0.025 & 0.062 & 0.039 & 0.039 & 15 \\
\hline FRS & Ion & 0.023 & $\mathrm{~F}$ & 0.006 & 0.023 & 0.053 & 0.032 & 0.034 & 15 \\
\hline FRS & Photo & 0.027 & $\mathrm{~F}$ & 0.056 & 0.120 & 0.165 & 0.117 & 0.061 & 15 \\
\hline FRS & Photo & 0.0295 & $\mathrm{~F}$ & 0.034 & 0.072 & 0.104 & 0.069 & 0.038 & 15 \\
\hline FRS & Ion & 0.0129 & $\mathrm{~S}$ & 0.098 & 0.205 & 0.267 & 0.212 & 0.125 & 11 \\
\hline FRS & Ion & 0.023 & $\mathrm{~S}$ & 0.032 & 0.094 & 0.164 & 0.100 & 0.074 & 12 \\
\hline FRS & Photo & 0.027 & $\mathrm{~S}$ & 0.038 & 0.089 & 0.160 & 0.100 & 0.058 & 13 \\
\hline FRS & Photo & 0.0295 & $\mathrm{~S}$ & 0.014 & 0.044 & 0.136 & 0.103 & 0.146 & 13 \\
\hline
\end{tabular}

${ }^{\mathrm{a}} \mathrm{F}=$ Flaming Fires; $\mathrm{S}=$ Smoldering Fires

Qualitatively examining this table, a tremendous amount of variation is evident in the measured ODM values at the time of alarm. This fact is evident by comparing the 
difference between the $20 \%$ and $80 \%$ OD Alarm Thresholds. Another important observation is that neither the variation nor central tendencies of the smoke optical density values at the time of alarm appear directly related to the nominal sensitivity level of the detectors. There is no clear pattern in the variation of the data, although the mean and median values generally increase with increasing nominal detector sensitivity (i.e., from a sensitivity level of $0.0071 \mathrm{OD} / \mathrm{m}$ to $0.0508 \mathrm{OD} / \mathrm{m}$ ).

Although not specifically presented in Table 1, there were numerous cases, for both flaming and smoldering fires, in which alarms occurred with ODM values of nearly zero. The importance of this fact is that, albeit in a rare number of cases, detection can occur very rapidly with little or no measurable smoke visible in the room. The implication of this from a modeling perspective is that ODM values (or smoke values from a model) may not be the most effective means to predict the earliest smoke detector alarm responses.

The OD Alarm Thresholds of 20\%, 50\%, and $80 \%$ were selected in order to provide a range of alarm thresholds that can be used for various applications. For example, if an estimate of an early detector response is to be made, then the $20 \%$ OD Alarm Threshold would be appropriate. In contrast, if a far more conservative estimate is desired in order to determine when the vast majority of detectors would have alarmed, then the $80 \%$ OD Alarm Threshold would be more appropriate. However, even in this instance it is important to remember that the $80 \%$ value does not capture the entire population of smoke detectors; some detectors will not have alarmed. Also, the temporal resolution of this estimate is typically worse than the $20 \%$ OD Alarm Threshold, meaning that there are detectors that would have alarmed long before the $80 \%$ OD Alarm Threshold is reached. Therefore using the $80 \%$ OD Alarm Threshold value could result in longer response time estimates of smoke detector alarms than would actually occur.

For many cases in which a typical smoke detector alarm response is desired, the 50\% OD Alarm Threshold would suffice. This will provide an estimate, at which half the detectors would have alarmed. Figures 1 and 2 respectively present bar charts of the 50\% OD Alarm Thresholds for the ionization and photoelectric detectors using the data in Table 1 . These figures are generally, qualitatively similar to those for the $20 \%$ and $80 \%$ thresholds [15]. Figure 1 shows that the ionization detectors alarmed closer to the nominal sensitivity value for flaming fires than for smoldering fires. Ionization detectors have historically been most sensitive to flaming fires, so this result is not all that surprising. The nominal detector sensitivities for the ionization detectors responding to flaming fires agreed closely with the 50\% OD Alarm Thresholds. However, as seen in both Fig. 1 and Fig. 2, for all other cases (ionization/smoldering, photoelectric/flaming, photoelectric /smoldering) the alarm thresholds are generally significantly higher than the nominal sensitivities. One trend that is similar for all OD Alarm Threshold levels (20\%, $50 \%$, and $80 \%$ ) is that there is a much larger difference between the OD Alarm Thresholds for flaming and smoldering fires for ionization detectors compared to the difference for the photoelectric detectors. The fact that the thresholds are less dependant on fire type for photoelectric detectors can be seen by comparing Fig. 1 and Fig. 2. 


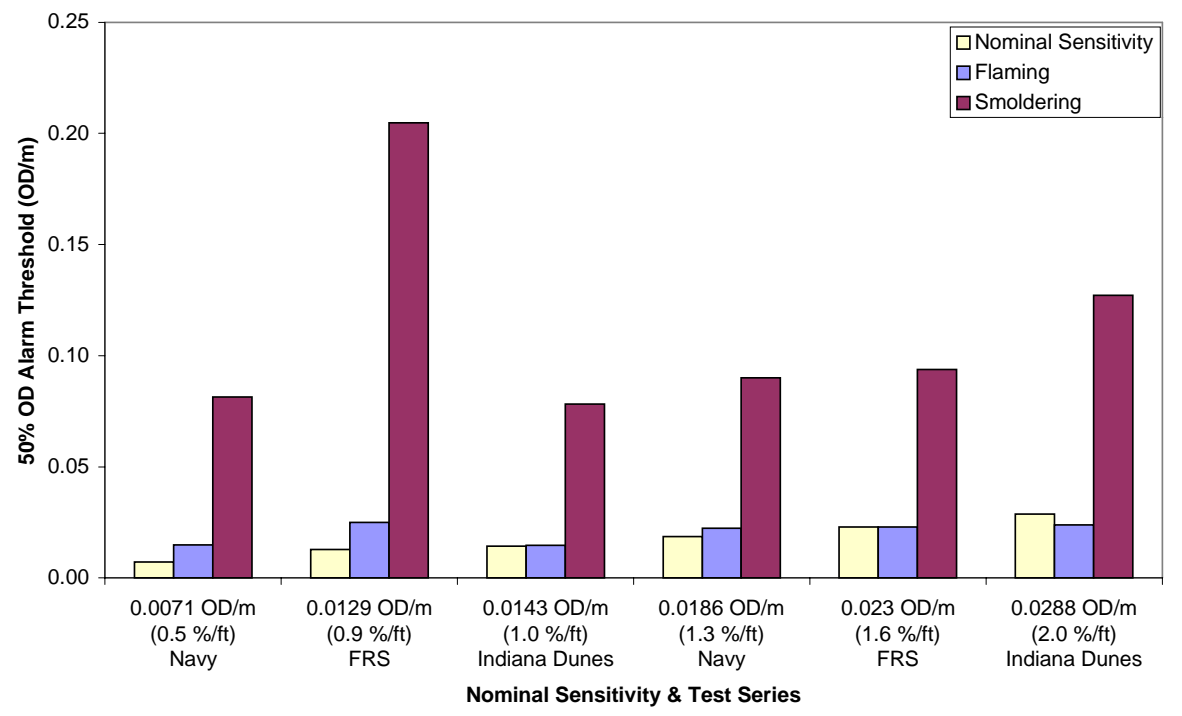

Fig. 1 - 50\% OD Alarm Thresholds for Ionization Detectors.

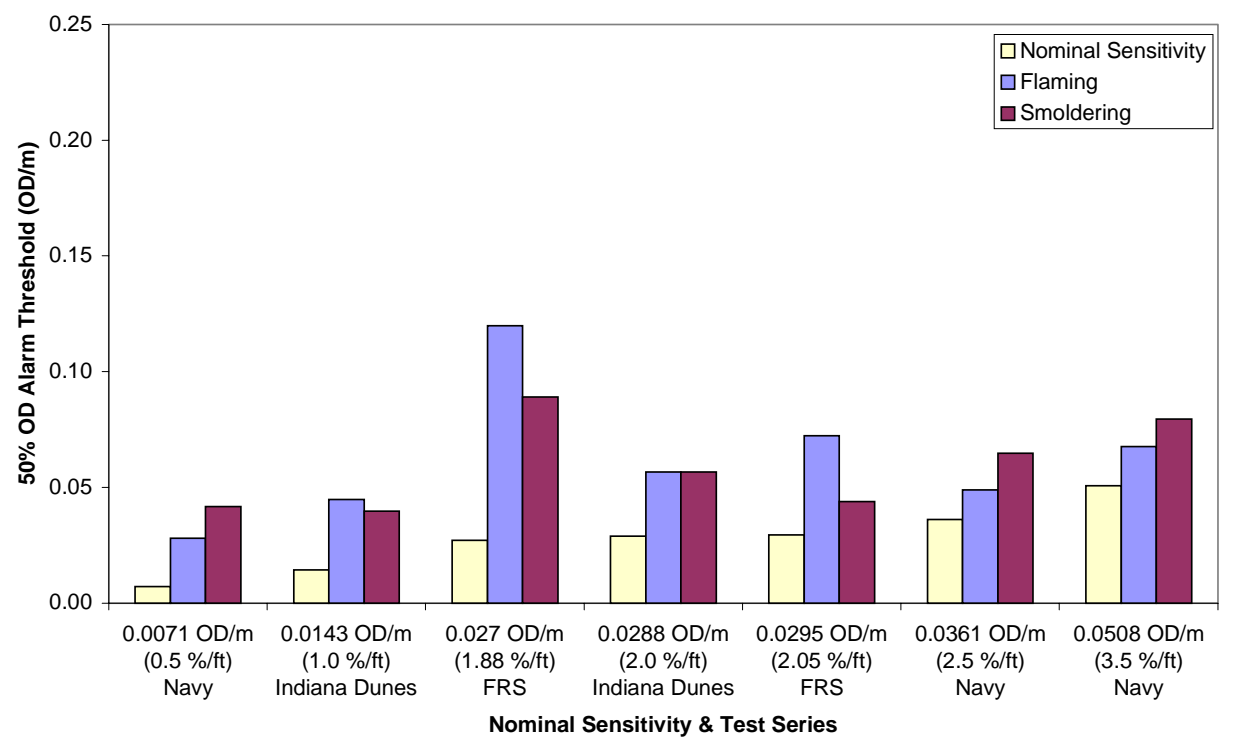

Fig. 2 - 50\% OD Alarm Thresholds for Photoelectric Detectors.

Using the different OD Alarm Thresholds provides a range of likely smoke detector alarm responses and a means to assess the associated certainty in the analysis being performed. For example, the use of both the $20 \%$ and $80 \%$ OD Alarm Thresholds will 
yield quasi-bounding alarm times that can be used to determine the range of impact on the timing of other critical events in a fire, such as the time to untenable conditions or egress. Likewise, OD Alarm Thresholds from the different test series could be used to gain an even broader range and understanding of the variability of possible detector alarms. When using values from Table 1 it is important to not only select OD Alarm Thresholds according to desired level of certainty or resolution in the prediction, but to also consider the smoke sources, detector technologies, and experimental setup used in each test series. For example, the Indiana Dunes test series took place in the mid-1970's and used the state-of-the-art detectors at that time. If the application at hand involves the use of current state-of-the-art smoke detectors, using OD Alarm Thresholds based on the Navy or FRS test series may be more appropriate. On the other hand, if considering smoke detectors in a residential environment, with typical smoke sources for this environment, the OD Alarm Thresholds from the Indiana Dunes or FRS tests series would likely be more representative. Judgment is left to the engineer to determine the most representative OD Alarm Thresholds for the specific application.

However, in an effort to provide further guidance on selecting general OD Alarm Thresholds, Table 3 is provided with the arithmetic means of the $20 \%, 50 \%$, and $80 \%$ OD Alarm Thresholds for each combination of detector and fire type from Table 1. Since no consistent or obvious relationship existed between the nominal sensitivity values and the OD Alarm Thresholds, this variable has been eliminated from Table 1. Therefore, the data represents nominal sensitivity values ranging from 0.0071 to $0.0288 \mathrm{OD} / \mathrm{m}(0.5$ to $2 \% / \mathrm{ft})$ for ionization detectors and from 0.0071 to $0.0508 \mathrm{OD} / \mathrm{m}(0.5$ to $3.5 \% / \mathrm{ft})$ for photoelectric detectors. These ranges capture most alarm settings for which the detectors will be used in practice. To understand the variability associated with using these mean OD Alarm Thresholds, Table 1 also includes the standard deviation for the mean. The standard deviations of the means are on the order of $50 \%$ of the mean, again reflecting the impact of the many variables that influence detector response (e.g., detector design, nominal sensitivity, and particulars of the test series, such as fuel type and configuration).

\section{Table 2 - Average OD Alarm Thresholds for All Test Series and Nominal Detector Sensitivities.}

\begin{tabular}{|l|l|l|l|}
\hline $\begin{array}{l}\text { OD Alarm } \\
\text { Threshold }\end{array}$ & Fire Type & Ionization Detectors & Photoelectric Detectors \\
\hline \hline \multirow{2}{*}{$20 \%$} & Flaming Fires & $0.007 \pm 0.004 \mathrm{OD} / \mathrm{m}$ & $0.031 \pm 0.016 \mathrm{OD} / \mathrm{m}$ \\
\cline { 2 - 4 } & Smoldering Fires & $0.045 \pm 0.028 \mathrm{OD} / \mathrm{m}$ & $0.032 \pm 0.016 \mathrm{OD} / \mathrm{m}$ \\
\hline \multirow{2}{*}{$50 \%$} & Flaming Fires & $0.021 \pm 0.005 \mathrm{OD} / \mathrm{m}$ & $0.063 \pm 0.029 \mathrm{OD} / \mathrm{m}$ \\
\cline { 2 - 4 } & Smoldering Fires & $0.113 \pm 0.048 \mathrm{OD} / \mathrm{m}$ & $0.059 \pm 0.019 \mathrm{OD} / \mathrm{m}$ \\
\hline \multirow{2}{*}{$80 \%$} & Flaming Fires & $0.072 \pm 0.027 \mathrm{OD} / \mathrm{m}$ & $0.106 \pm 0.039 \mathrm{OD} / \mathrm{m}$ \\
\cline { 2 - 4 } & Smoldering Fires & $0.176 \pm 0.052 \mathrm{OD} / \mathrm{m}$ & $0.110 \pm 0.034 \mathrm{OD} / \mathrm{m}$ \\
\hline
\end{tabular}

\section{Nominal Detector Sensitivity as Alarm Threshold}

It is evident that using the nominal sensitivity as the alarm threshold provides extremely poor results. A majority of the $20 \%$ OD Alarm Thresholds ( 15 of 26) were greater than the nominal sensitivity levels of the detectors. This indicates that the use of the nominal sensitivity as an alarm threshold prematurely predicted detector alarms in the majority of cases. However, unlike the $20 \%$ OD Alarm Threshold, the percentage of detectors that 
alarmed when the nominal sensitivity was used as an alarm threshold varied widely (between $0 \%$ and 53\%) across the cases studied [15]. In only two cases would the nominal sensitivity have been even $50 \%$ effective at predicting detector alarms. Both of these cases were for flaming fires being detected by ionization detectors (see Fig. 1). Except for ionization detectors with flaming fires, using the nominal sensitivity of the detector as the alarm threshold with ODM data would only have been approximately $21 \%$ effective at signifying an actual alarm, based on the data studied. The use of the nominal detector sensitivity as an alarm threshold will generally result in predicting alarms before they actually occur. For this reason, it is not recommended that the nominal sensitivity of the detector be used as an alarm threshold in modeling efforts that aim to characterize typical detector responses or to confirm that the majority of detectors would alarm. The exception being typical responses (i.e., 50\%) of ionization detectors with flaming fires can be reasonably predicted using the nominal sensitivity.

\subsection{OD/m as Alarm Threshold}

The alarm threshold of $0.14 \mathrm{OD} / \mathrm{m}(9.4 \% / \mathrm{ft})$ was evaluated by comparing it to the optical density measurements at the time of alarm for all cases presented in Table 1. Figures 3 and 4 depict the percentage of detectors that would have been in alarm at a smoke optical density value of $0.14 \mathrm{OD} / \mathrm{m}$ for ionization and photoelectric detectors, respectively. In contrast to using the nominal detector sensitivity, the alarm threshold of $0.14 \mathrm{OD} / \mathrm{m}$ provides a much higher level of certainty that a detector will have alarmed. At a measured smoke optical density of $0.14 \mathrm{OD} / \mathrm{m}, 91$ percent of the ionization detectors alarmed for flaming fires and 65 percent for smoldering fires. Similarly, 86 percent of the photoelectric detectors alarmed for flaming fires and 85 percent for smoldering fires at a measured smoke optical density of $0.14 \mathrm{OD} / \mathrm{m}$. For all but one case, Fig. 4 shows that over 75 percent of the photoelectric detectors alarmed for both flaming and smoldering fires. Comparing Fig. 4 to Fig. 3, the photoelectric alarm results appear to be less dependent on fire type than the ionization detectors.

Though an alarm threshold of $0.14 \mathrm{OD} / \mathrm{m}$ provides a relatively high level of confidence in predicting detector alarms, the value is not necessarily optimized or narrowly defined. For example, many detectors actually alarmed at ODM values less than $0.14 \mathrm{OD} / \mathrm{m}$ (see Table 1, Fig. 1 and Fig. 2). Therefore, the use of this alarm threshold will lead to estimated alarm response times that are potentially longer than would actually occur. The difference in the alarm times is quite dependent on the fire growth and the resulting rate of smoke production. 


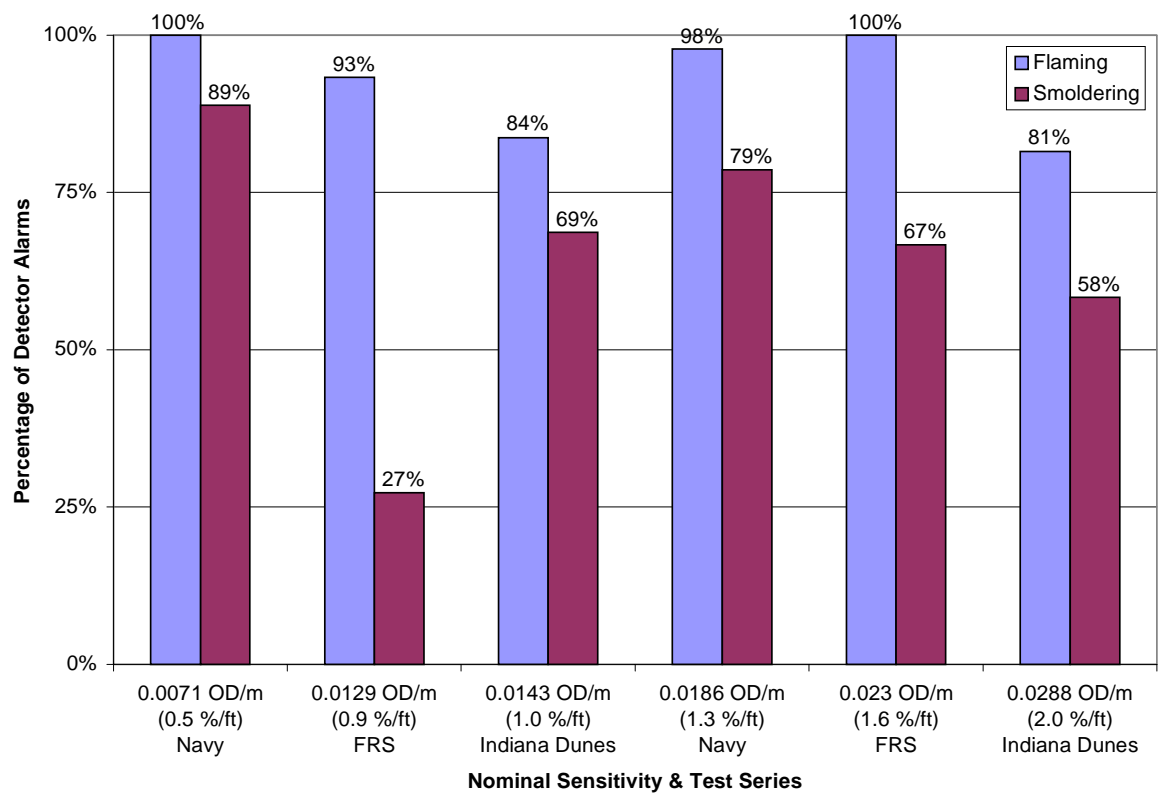

Fig. 3 - Percentage of Ionization Detector Alarms Occurring at or below an Alarm Threshold of 0.14 OD/m (9.4 \%/ft) based on Smoke Optical Density Measurements Outside the Detector

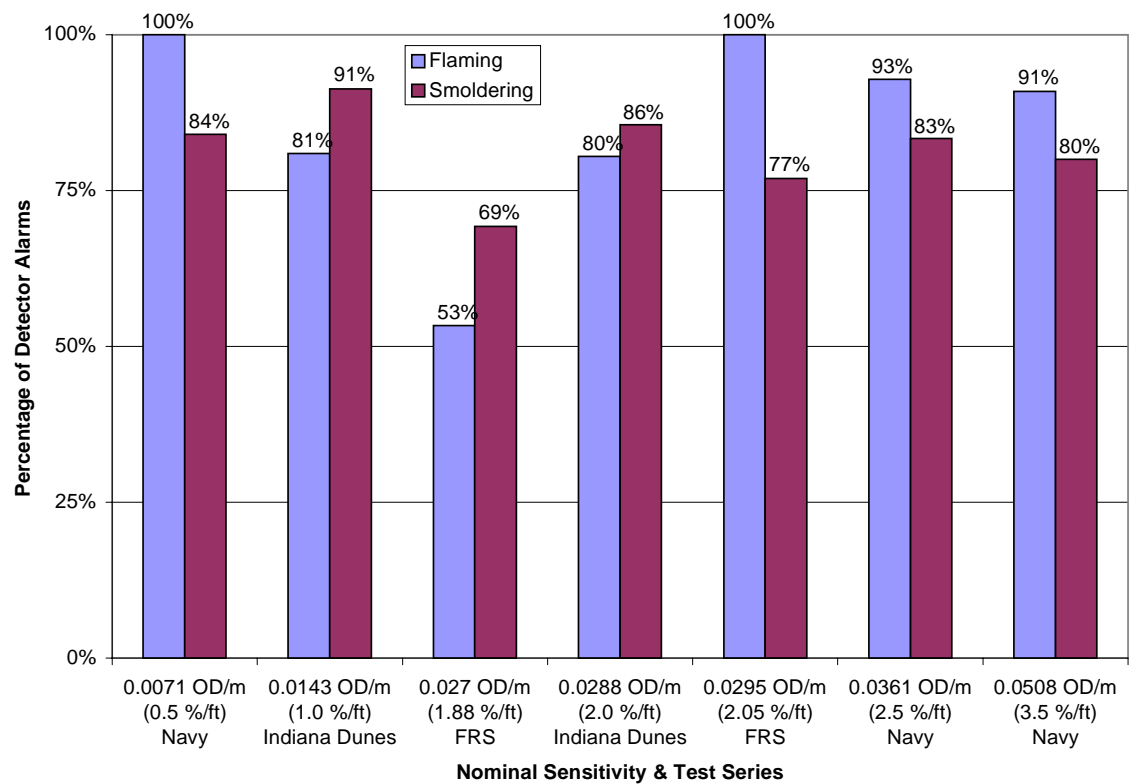

Fig. 4 - Percentage of Photoelectric Detector Alarms Occurring at or below an Alarm Threshold of $0.14 \mathrm{OD} / \mathrm{m}(9.4 \% / \mathrm{ft})$ based on Smoke Optical Density Measurements Outside the Detector 


\section{CONCLUSIONS}

This study provides a quantitative basis to assess the level of accuracy of defining a threshold smoke optical density outside a detector at which a smoke detector would be expected to alarm. Due to the variability in the existing experimental data, prediction of smoke detector alarms using calculated smoke optical densities near a detector should only be treated as an estimate. Determining precise alarm times is not currently possible with the large number of variables that exist.

This study has provided smoke optical density thresholds from full-scale tests that represent levels for which 20,50 and $80 \%$ of the detectors alarmed. Variables that were evaluated included detector type, fire type and nominal detector sensitivity. The results show that a single optical density alarm threshold does not exist which can be used to accurately predict detector alarms for all detectors. However, the results provide thresholds and the associated uncertainties for detector responses based on detector type, fire type and the level of response desired (i.e., 20, 50 or $80 \%$ of detectors alarming). The appropriate threshold is dependent on the application being evaluated.

Based on the results of this study, the use of the nominal detector sensitivity as an alarm threshold will lead to only about 20 percent of the alarm predictions corresponding to actual detector alarms. In most cases, the use of the nominal sensitivity will result in predicting alarms before they actually occur. The exception is that using the nominal sensitivity with ionization detectors responding to flaming fires will predict alarm conditions for approximately 50 percent of the cases.

The use of an alarm threshold of $0.14 \mathrm{OD} / \mathrm{m}(9.4 \% / \mathrm{ft})$ as proposed in the literature provides a reasonable estimate of when a majority of smoke detectors will alarm. At 0.14 $\mathrm{OD} / \mathrm{m}, 91$ percent of the ionization detectors alarmed for flaming fires and 65 percent for smoldering fires. Similarly, 86 percent of the photoelectric detectors alarmed for flaming fires and 85 percent for smoldering fires.

\section{REFERENCES}

1. Schifiliti, R.P., Meacham, B.J.,and Custer, R.L.P., "Design of Detection Systems," SFPE Handbook of Fire Protection Engineering, Section 4, Chapter 1, $2^{\text {nd }}$ Edition, 1995.

2. NFPA 72, Appendix B, National Fire Alarm Code, National Fire Protection Association, Quincy, MA, 1999.

3. Heskestad G., Delichatsios, M.A., Environments of Fire Detectors, Phase I: Effects of Fire Size, Ceiling Heights, and Material, Volume II - Analysis Technical Report Serial Number 11427, RC-T-11, Factory Mutual Research Corp., Norwood, MA, 1977.

4. Beyler, C., and DiNenno, P., "Letters to the Editor", Fire Technology, Volume 27, Number 2, pp. 160-169, May 1991.

5. Schifiliti, R.P., and Pucci, W.E., "Fire Detection Modeling: State of the Art", Fire Detection Institute, Bloomfield, CT, 1996.

6. Luck, H. and Sievert, U., "Does an Over-All Modeling Make Any Sense in Automatic Fire Detection?," AUBE '99 Proceedings of the 11th International 
Conference on Automatic Fire Detection, Gerhard Mercator Universität Duisburg, pp. 1-21, 1999.

7. Schifiliti, R.P., "Fire Detection Modeling - The Research-Application Gap, AUBE '01 Proceedings of the 12th International Conference on Automatic Fire Detection, National Institute of Standards and Technology, Gaithersburg, Maryland, pp. 529560, March 2001.

8. Cholin, J.M., and Marrion, C., "Performance Metrics for Fire Detection," Fire Protection Engineering, pp. 21-30, Number 11, Summer 2001.

9. Mowrer , F.W., and Friedman, J., "Experimental Investigation of Heat and Smoke Detector Response," Proceedings of Fire Suppression and Detection Research Application Symposium, Orlando, FL, February 24-26, pp. 256-264, 1998

10. Gottuk, D.T., Hill, S.A., Schemel, C.F., Strehlen, B.D., Rose-Phersson, S.L., Shaffer, R.E., Tatem, P.A., and Williams, F.W., "Identification of Fire Signatures for Shipboard Multi-criteria Fire Detection Systems," Naval Research Laboratory, Memorandum Report, 6180-99-8386, Washington, D.C., June 18, 1999.

11. Wakelin, A.J., "An Investigation of Correlations for Multi-Signal Fire Detectors," M.S. Thesis, Fire Protection Engineering, Worcester Polytechnic Institute, Worcester, MA, February 1997.

12. UL 217, "Standard for Single and Multiple Station Smoke Alarms," Fifth Edition dated February 21, 1997 with revisions through January 4, 1999, Underwriters Laboratories Inc., Northbrook, IL, January 4, 1999.

13. UL 268, "Standard for Smoke Detectors for Fire Protective Signaling Systems," Fourth Edition, Underwriters Laboratories Inc., Northbrook, IL, December 30, 1996.

14. Spearpoint, M.J., and Smithies, J.N., "Practical Comparison of Domestic Smoke Alarm Sensitivity Standards," Fire Research Station, Home Office Fire Research and Development Group, FRDG Publication No. 4/97, 1997.

15. Geiman, J.A., and Gottuk, D.T., "Alarm Thresholds for Smoke Detector Modeling," Hughes Associates, Inc., Internal Report 0601-2002-01, 2002.

16. Bukowski, R.W., Waterman, T.E., and Christian, W.J., "Detector Sensitivity and Siting Requirements for Dwellings", Final Technical Report, IITRI Project J6340, Contract No. 4-36092, NBS-GCR-75-51, National Bureau of Standards, Gaithersburg, MD, 1975.

17. Rose-Phersson, S.L., Shaffer, R.E., Hart, S.J., Williams, F.W., Gottuk, D.T., Strehlen, B.D., and Hill, S.A., "Multi-Criteria Fire Detection Systems Using a Probalistic Neural Network," Sensors and Acuators B 69, 2000 pp. 325-335.

18. Wong, J.T., Gottuk, D.T., Rose-Pehrsson, S.L., Shaffer, R.E., Hart, S., Tatem, P.A., Williams, F.W., "Results of Multi-Criteria Fire Detection System Tests," Naval Research Laboratory, May 2000.

19. Carhart, H.W., Toomey, T.A., and Williams, F.W., "The ex-USS SHADWELL Fullscale Fire Research and Test Ship," NRL Memorandum Report 6074, revised January 20, 1988, reissued 1992.

\section{ACKNOWLEDGMENTS}

The authors thank Mike Spearpoint and the Fire Research Station for graciously providing electronic forms of data, which facilitated this study. 